\title{
The importance of epithelial-mesenchymal transition and autophagy in cancer drug resistance
}

\author{
Charlotte Hill', Yihua Wang ${ }^{1,2}$ \\ 'School of Biological Sciences, Faculty of Environmental and Life Sciences, University of Southampton, Southampton SO17 \\ 1BJ, UK. \\ ${ }^{2}$ Institute for Life Sciences, University of Southampton, Southampton SO17 1BJ, UK.
}

Correspondence to: Dr. Yihua Wang, School of Biological Sciences, Faculty of Environmental and Life Sciences, University of Southampton, Southampton SO17 1BJ,UK. E-mail: yihua.wang@soton.ac.uk

How to cite this article: Hill C, Wang Y. The importance of epithelial-mesenchymal transition and autophagy in cancer drug resistance. Cancer Drug Resist2020;3:38-47. http://dx.doi.org/10.20517/cdr.2019.75

Received: 9 Sep 2019 First Decision: 5 Nov 2019 Revised: 13 Nov 2019 Accepted: 13 Dec 2019 Published: 19 Mar 2020

Science Editor: William Henry Gmeiner Copy Editor: Jing-Wen Zhang Production Editor: Tian Zhang

\begin{abstract}
Epithelial-mesenchymal transition (EMT) and autophagy are both known to play important roles in the development of cancer. Subsequently, these processes are now being utilised as targets for therapy. Cancer is globally one of the leading causes of death, and, despite many advances in treatment options, patients still face many challenges. Drug resistance in cancer-therapy is a large problem, and both EMT and autophagy have been shown to contribute. However, given the context-dependent role of these processes and the complexity of the interactions between them, elucidating how they both act alone and interact is important. In this review, we provide insight into the current landscape of the interactions of autophagy and EMT in the context of malignancy, and how this ultimately may affect drug resistance in cancer therapy.
\end{abstract}

Keywords: Epithelial-mesenchymal transition, autophagy, cancer drug resistance, metastasis, therapy

\section{EPITHELIAL-MESENCHYMAL TRANSITION}

Epithelial-mesenchymal transition (EMT) is an important biological process, which is critical in developmental biology and wound healing, but has also been implicated in fibrosis and malignancy ${ }^{[1-4]}$. It is a reversible biological process associated with loss of cell polarity and cadherin-mediated cell adhesion in epithelial cells. These cells transition to mesenchymal cells and, in turn, gain migratory and invasive abilities $^{[5]}$. EMT is mediated through a number of signalling pathways, including transforming growth

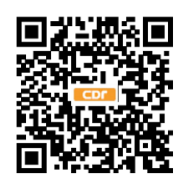




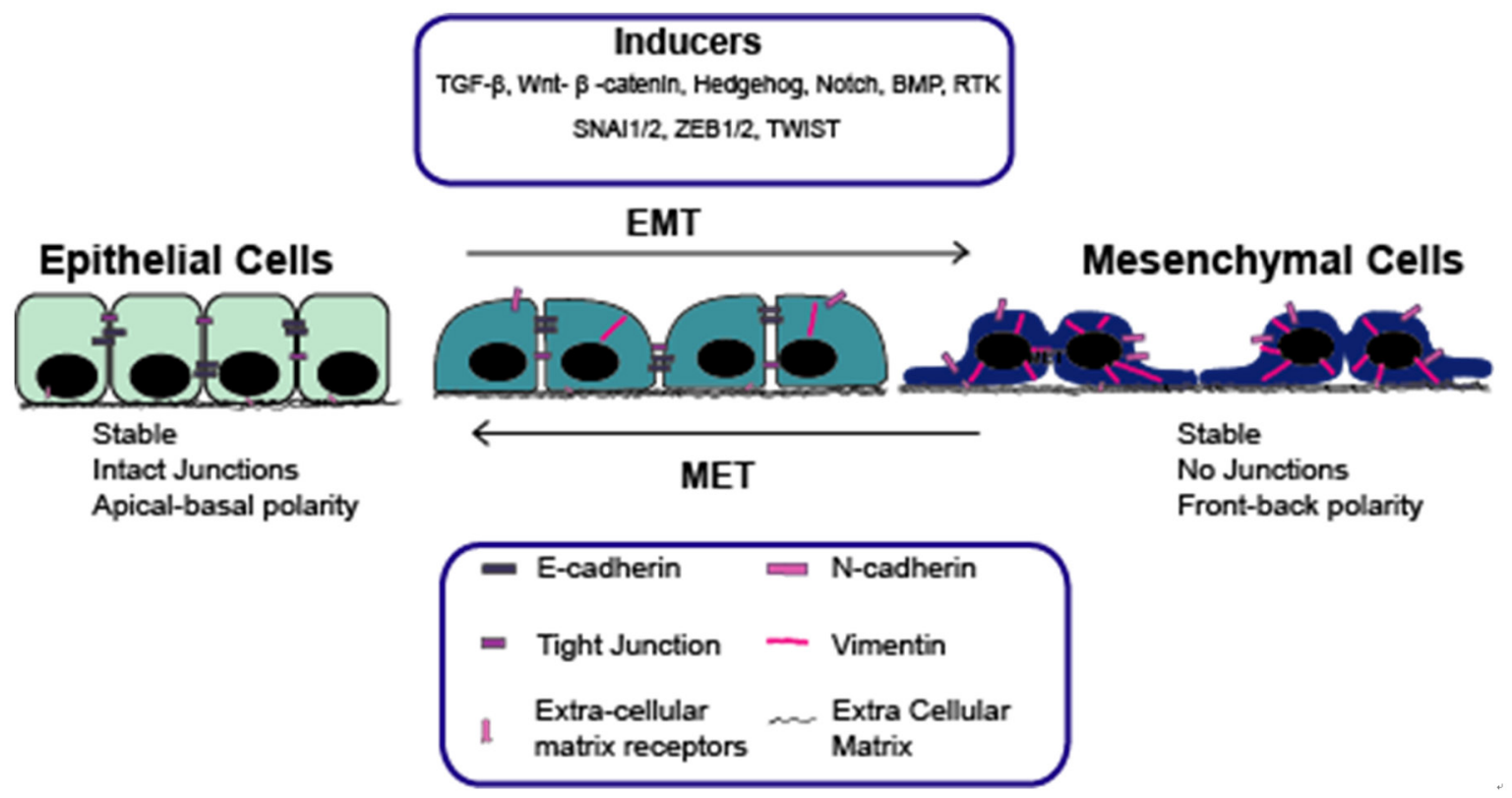

Figure 1. The role of EMT and MET in malignancy, with key biological features and EMT-inducers highlighted. EMT: epithelialmesenchymal transition; MET: mesenchymal-epithelial transition

Factor-beta (TGF- $\beta$ ), Wnt- $\beta$-catenin, Hedgehog (Hh), Notch, Bone Morphogenetic Protein and receptor tyrosine kinases $^{[6]}$. Signalling pathways in turn mediate EMT specific transcription factors (EMT-TFs) such as Zinc finger E-box-binding homeobox 1/2 (ZEB1/2), Snail Family Transcriptional Repressor 1/2 (SNAIL1/2) and Twist, which subsequently act to repress the expression of target genes, including E-cadherin. Loss of E-cadherin is considered a key step in $\mathrm{EMT}^{[6-9]}$. In the context of malignancy, EMT can result in cells metastasising from primary tumour sites, which has been associated with a worse prognosis [Figure 1].

\section{AUTOPHAGY}

Autophagy is an evolutionarily-conserved biological process where long-lived proteins and damaged organelles are degraded by the lysosome $e^{[10,11]}$. There are two types of autophagy: general and selective autophagy. In general autophagy, part of the cytoplasm is engulfed, which is delivered to the lysosome and this is degraded. (Macro) autophagy is where a double-membraned vesicle is formed, which captures material in the cytoplasm to be degraded, whereas selective autophagy specifically targets cargo to be degraded ${ }^{[12-15]}$. Autophagy has also been proposed to have roles in a number of diseases ${ }^{[16]}$, such as fibrosis ${ }^{[17-19]}$, neurodegeneration ${ }^{[20]}$ and cancer ${ }^{[21,22]}$ [Figure 2].

The role of autophagy in malignancy is complicated, with conflicting reports on its role in different contexts $^{[23-27]}$. It is thought that autophagy largely aids in tumour suppression in early tumorigenesis, whereas it can promote tumour progression and cancer-cell survival in the later stages. It is understood that autophagy is able to prevent the formation of tumours by maintaining stability in normal cells. During early stages, autophagy protects normal cells from transforming by preventing genomic instability, and thus preventing formation of an inflammatory microenvironment. In comparison, in the later stages, autophagy helps survival of cancerous cells undergoing a number of cellular stresses such as metabolic stress and prevents cell death by anoikis ${ }^{[28,29]}$.

Increased autophagy has been associated with cancer as a mechanism to aid survival and resist treatment ${ }^{[30]}$, with tumours being shown to require autophagy for survival ${ }^{[31,32]}$. As such, autophagy inhibitors have 


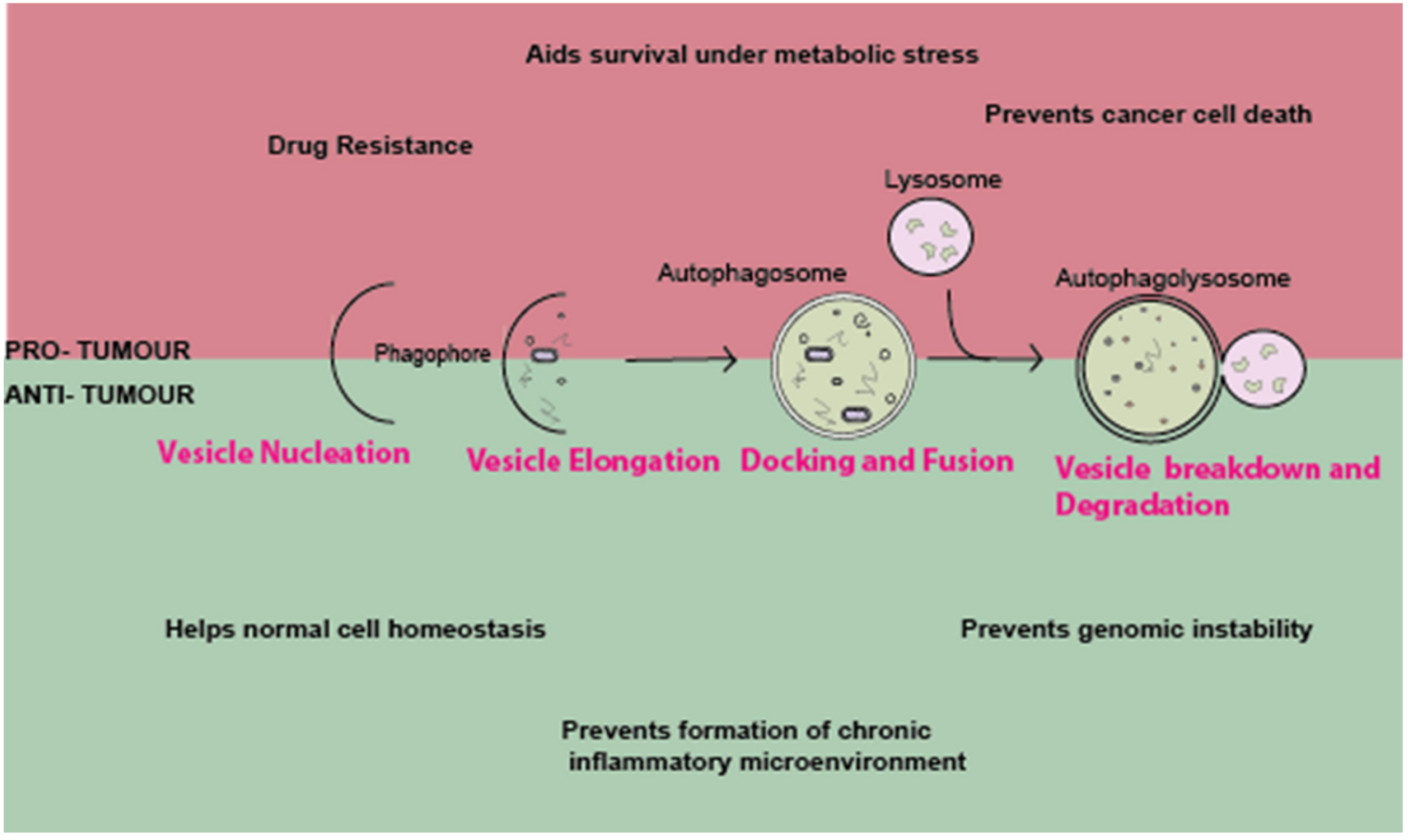

Figure 2. The role of autophagy in cancer: the formation of a double-membrane to engulf material to be degraded by the lysosome by autophagy. The role of autophagy in cancer is complex and has both a pro- and anti-tumour effects. Further discussion in review

been utilised both alone and in combination with traditional therapy. Several studies demonstrated that autophagy inhibition is able to sensitise cancer cells to further treatment ${ }^{[33-35]}$.

\section{EMT AND AUTOPHAGY: A COMPLEX RELATIONSHIP IN MALIGNANCY}

The signalling pathways of both EMT and autophagy are complex and can be induced in a number of ways; it is therefore unsurprising that there is some interaction between these two pathways ${ }^{[36,37]}$. Numerous studies in different contexts have demonstrated interactions between autophagy and EMT, although it does appear this is both context- and tissue-dependent [Table 1]. Studies have shown that manipulation of autophagy can promote EMT, invasion and metastasis ${ }^{[21,27,38-40]}$; these have been demonstrated in a wide variety of tissues/cell lines including pancreatic, breast, colorectal, melanoma and gastric. In total, 1400 tumours from 20 different types of cancers were analysed for LC3B, an autophagy marker, and it was found that increased expression was associated with metastasis and invasion ${ }^{[27]}$. Autophagy inhibition in rat sarcoma-mutant cancer cells was demonstrated to induce EMT by triggering NF- $\kappa$ B by $\mathrm{p} 62 / \mathrm{SQSTM}{ }^{[21]}$. Similarly, p62/SQSTM1 is important for stabilising Twist1, preventing its degradation ${ }^{[40]}$. In gastric cancer cells, autophagy inhibition promotes EMT and alters the metabolic phenotype of cells, and this is dependent on ROS-NF- $\mathrm{B}-\mathrm{HIF}-1 \alpha^{[38]}$. In colon cancer cells, Beclin-1 has been shown to be associated with EMT and invasive behaviours; loss of Beclin-1 was able to reverse this phenotype ${ }^{[41]}$. As described above, autophagy has a dual role: in pancreatic ductal adenocarcinoma cells, TGF- $\beta 1$ induced autophagy in SMAD4-positive cells and inhibited migration by reducing nuclear translocation of SMAD family member 4 (SMAD4), whereas, in SMAD4-negative cells, migration was increased through mitogen-activated protein kinase/extracellular signal-regulated kinase $(\mathrm{ERK})^{[42]}$.

Manipulation of autophagy has also been demonstrated to prevent an EMT-like phenotype and associated metastasis/invasion in a number of cancer cell lines and tissues, including breast, colorectal, pancreatic and ovarian cancers ${ }^{[42-48]}$. In hepatocellular carcinoma, autophagy inhibition was not shown to induce EMT and had no effect on migration or invasion ${ }^{[43]}$. Death effector domain-containing DNA-binding protein attenuates EMT by interacting with Beclin-1 (BECN) and PIK3C3 and activating autophagy ${ }^{[44]}$. In ovarian 
Table 1. Autophagy and EMT: the dual role in cancer. Autophagy has been described to have both pro- and anti-tumour effects; some of the recent works in a variety of tissue types where the dual role of autophagy in malignancy has been demonstrated are highlighted

\begin{tabular}{|c|c|c|c|}
\hline Autophagy & Role on EMT & Cell/Tissue type & Study \\
\hline \multicolumn{4}{|l|}{ Promotes EMT } \\
\hline Inhibition of autophagy & Promotes metastasis through induction of ROS & Gastric cells & [38] \\
\hline Increased LC3B expression & Associated with metastasis & $\begin{array}{l}\text { Breast cancer, melanoma and } 18 \\
\text { other cancers }\end{array}$ & [27] \\
\hline Autophagy inhibition (ATG KD, histology) & Promotes EMT and invasion & $\begin{array}{l}\text { Colorectal cancer, pancreatic cancer } \\
\text { (in RAS-mutated cells) }\end{array}$ & [21] \\
\hline Autophagy induced by TGF- $\beta$ & Promotes EMT & $\mathrm{NSCL}$ & [39] \\
\hline Autophagy inhibited (ATG KD) & Promotes EMT via Twist & MEFs, keratinocytes, melanoma cells & [40] \\
\hline Autophagy induced by TGF- $\beta$ & $\begin{array}{l}\text { Inhibited proliferation, increased migration by } \\
\text { MAPK/ERK activation }\end{array}$ & Pancreatic cancer (SMAD4-neg) & [42] \\
\hline Inhibition by BECN1 & Prevents EMT & Colorectal cancer & [41] \\
\hline \multicolumn{4}{|l|}{ Prevents EMT } \\
\hline Autophagy inhibition & Prevents metastasis & Hepatocellular carcinoma & [43] \\
\hline Activated autophagy & Prevents EMT by Snail and Twist & Breast & [44] \\
\hline Autophagy induced by TGF- $\beta$ & Inhibited migration, promoted proliferation & Pancreatic cancer (SMAD4-pos) & [42] \\
\hline $\begin{array}{l}\text { Autophagy induced by Danusertib (pan-inhibiter } \\
\text { of Aurora kinases) }\end{array}$ & EMT inhibited, potentially via PI3K/Akt/mTOR & Ovarian carcinoma & [45] \\
\hline Increased autophagy by overexpression of FAT4 & $\begin{array}{l}\text { Prevents EMT. Regulatory effects of FAT } 4 \text { on } \\
\text { autophagy and EMT are partially by PI3K-AKT }\end{array}$ & Colorectal cancer & [46] \\
\hline Increased autophagy & $\begin{array}{l}\text { Protects cells from anoikis, promoting luminal } \\
\text { filling in early carcinoma }\end{array}$ & Breast cancer & [47] \\
\hline
\end{tabular}

EMT: epithelial-mesenchymal transition; ROS: reactive oxygen species; NSCL: non-Small cell lung cancer; TGF- $\beta$ : Transforming growth factor beta; MAPK: mitogen-activated protein kinase; ERK: extracellular signal-regulated kinase; MEFs: mouse embryonic fibroblasts; RAS: rat sarcoma; ATG: autophagy-related gene; KD: knockdown; PI3Ks: phosphoinositide 3-kinases; AKT: AKT serine/threonine kinase; mTOR: mechanistic target of rapamycin kinase; BECN: Beclin-1; FAT4: FAT atypical cadherin 4

carcinoma, danusertib induced autophagy, which resulted in suppression of EMT and arrest of G2/M phase, and this may be in part due to $\mathrm{P} 13 \mathrm{~K} / \mathrm{Akt} / \mathrm{mTOR}$ signalling ${ }^{[45]}$. Similarly, FAT4 has been shown to regulate activity of phosphoinositide 3-kinases (PI3K) to induce autophagy and inhibit $\mathrm{EMT}^{[49]}$.

Given the complicated role of autophagy in malignancy and how several clinical trials are now utilising autophagy inhibitors as treatments for cancer (http://www.cancer.gov/clinicaltrials), the wider-reaching implications of these drugs need to be further investigated.

\section{DRUG RESISTANCE: WHERE DOES EMT COME INTO PLAY?}

Drug resistance is a well-known concept where diseases become unaffected by pharmaceutical treatment, which has been studied in a variety of disease models. Two types of drug resistance have been described: acquired and de novo ${ }^{[50]}$. Initially, many cancers can be treated with "conventional" therapies such as chemotherapy; however, as the biochemical and tumour environments adapt overtime, sometimes cancer cells become resistant to these treatments. This resistance can be due to many factors, not limited to: drug efflux, metabolism, changes in drug target, DNA damage repair, cell death inhibition and $\mathrm{EMT}^{[51]}$.

The link between EMT and drug resistance in cancer was proposed in the $1990 \mathrm{~s}^{[52]}$ and, subsequently, it has been reported that drug resistance in different cancers is associated with EMT, including lung ${ }^{[53]}$, pancreatic ${ }^{[54,55]}$, bladder ${ }^{[56]}$ and breast cancers ${ }^{[57,58]}$. Activation of several signalling pathways known to induce EMT, such as TGF- $\beta$, Wnt, Hh and Notch ${ }^{[59-62]}$, has also been demonstrated to induce cancer drug. Some of the specific mechanisms have begun to be elucidated, but, due to the large variety of drugs, tissue types and signalling pathways involved, it is a complex process, as summarised in Table 2.

TGF- $\beta$ signalling has been implicated in different tissues including colorectal, breast and squamous cell carcinoma stem cells ${ }^{[59,63-66]}$, although mechanistically its involvement in drug resistance has been varied. Some studies demonstrated a role for metabolism, showing that TGF- $\beta$ regulated 5-Fluorouracil (5- 
Table 2. EMT signalling pathways and EMT-TFs: contributions to drug resistance. Several recent studies describe EMT pathways and transcription factors which have been demonstrated to be involved in drug resistance in cancer

\begin{tabular}{|c|c|c|c|}
\hline & Mechanism of resistance & Tissue type & Study \\
\hline \multicolumn{4}{|c|}{ Signalling pathway } \\
\hline \multirow[t]{5}{*}{ TGF- $\beta$} & Upregulation of TGF $\beta$ & Colon cancer cells & {$[59]$} \\
\hline & - & Triple negative breast cancer & {$[63]$} \\
\hline & - & Squamous cell carcinoma stem cells & {$[64]$} \\
\hline & - & Breast cancer cells (HMLER) & {$[65]$} \\
\hline & Regulating the expression of PDK4 & Colorectal cancer & {$[66]$} \\
\hline \multirow[t]{3}{*}{ Wnt } & $\begin{array}{l}\text { Trastuzumab resistance associated with Wnt3 overexpression activates Wnt/ } \\
\beta \text {-catenin which transactivates EGFR }\end{array}$ & HER2-over expressing breast cancer & {$[60]$} \\
\hline & $\begin{array}{l}\text { Resistance to platinum-based chemotherapies. DACT1 demonstrated to be a } \\
\text { negative regulator in EOC, inhibiting Wnt signalling and cis-platinum resistance } \\
\text { through regulation of autophagy }\end{array}$ & Type I epithelial ovarian cancer (EOC) & {$[67]$} \\
\hline & $\begin{array}{l}\text { NANOGP8 is main regulator. It is closely related to EMT and the Wnt pathway, } \\
\text { and correlates with migration, invasion and chemo resistance in gastric cancer }\end{array}$ & Gastric cancer cells & {$[68]$} \\
\hline \multirow[t]{2}{*}{$\mathrm{Hh}$} & Hh pathway activated in EGFR-WT and EGFR-MT lung cancer & NSCLC & {$[61]$} \\
\hline & $\begin{array}{l}\text { Hh pathway activation, EGFR and EPHB3 crosstalk through Hh-STAT3. } \\
\text { However, loss of Hh may result in cells being more EGFR-dependent }\end{array}$ & Colorectal cancer & {$[69]$} \\
\hline Notch & Activation of notch signalling & Pancreatic cancer & [62] \\
\hline \multicolumn{4}{|l|}{ EMT-TF } \\
\hline \multirow[t]{4}{*}{ TWIST } & - & Colorectal carcinoma & {$[70]$} \\
\hline & TWIST upregulation & Nasopharyngeal carcinoma & {$[71]$} \\
\hline & Activated Twist mediates P-glycoprotein expression & Bladder cancer & {$[72]$} \\
\hline & - & Breast cells & {$[73]$} \\
\hline \multirow[t]{4}{*}{ Snail1/2 } & - & Ovarian adenocarcinoma & {$[74]$} \\
\hline & - & HGSOC & {$[75]$} \\
\hline & - & Oral squamous cell carcinoma & {$[76]$} \\
\hline & $\begin{array}{l}\text { ABC transporters are overexpressed in cancer and can remove cytotoxic drugs } \\
\text { by ATP-dependent efflux. EMT-TF such as TWIST, SNAIL and FOXC2 have been } \\
\text { demonstrated to increased levels of ABC transporters, which are directly related } \\
\text { to drug resistance }\end{array}$ & Breast & {$[77,78]$} \\
\hline \multirow[t]{2}{*}{ ZEB1 } & $\begin{array}{l}\text { ZEB1-miR200 feedback loop. ROBO1, OLIG2, CD133 and MGMT identified as } \\
\text { novel ZEB1 targets }\end{array}$ & Glioblastoma & {$[79]$} \\
\hline & Increased IL-1 $\beta$ increases ZEB1 and was associated with increased resistance & Colon cancer & {$[80]$} \\
\hline ZEB2 & Loss of FBXW7 & Colorectal cancer & {$[81]$} \\
\hline
\end{tabular}

PDK4: pyruvate dehydrogenase kinase 4; DACT1: dapper1 antagonist of catenin 1; EOC: epithelial ovarian cancer; EMT: epithelialmesenchymal transition; EMT-TF: EMT specific transcription factor; NSCLC: non-small cell lung cancer; Hh: hedgehog; HGSOC: high grade serous ovarian cancer; Wnt: Wingless/Int1; EGFR: epidermal growth factor receptor; WT: wild type; MT: mutant; ABC: ATPbinding cassette; EPHB3: EPH Receptor B3; STAT3: signal transducer and activator of transcription 3; FOXC2: forkhead box C2; ZEB: zinc finger E-box binding homeobox; ROBO1: roundabout guidance receptor 1; OLIG2: oligodendrocyte transcription factor 2; MGMT: O-6methylguanine-DNA methyltransferase; IL-1 13 : interleukin 1 beta; FBXW7: F-box and WD repeat domain containing 7

FU) resistance in colorectal cancer (CRC) through the regulation of pyruvate dehydrogenase kinase $4^{[66]}$. In squamous cell carcinoma, TGF- $\beta$ transcriptionally activates p21, which stabilises NRF2, enhancing glutathione metabolism and reducing the effectiveness of therapies ${ }^{[64]}$. Conversely, downregulation of Smad4 was demonstrated to increase sensitivy in doxorubicin (Dox) resistant colon cancer, which had been shown to be via TGF- $\beta^{[59]}$. In triple negative breast cancer, TGF- $\beta$ was shown to be critical in epirubicin resistance by regulating EMT and apoptosis ${ }^{[63]}$. Long-term TGF- $\beta$ treatment has also been associated with anti-cancer drug resistance ${ }^{[65]}$.

Several other EMT-inducing pathways have also been directly linked to drug resistance in cancer. Wnt has been demonstrated to cause drug resistance in HER2-overexpressing breast cancer, Type-1 epithelial ovarian cancer (EOC) and gastric cancer ${ }^{[60,67,68]}$. In HER2-overexpressing breast cancer cells, it is considered that Wnt3 overexpression may activate Wnt/ $\beta$-catenin transactivating EGFR, which can lead to a partialEMT that could be important in understanding trastuzumab resistance in these cells ${ }^{[60]}$. In EOCs, Dapper1 Antagonist of Catenin1 (DACT1) has been shown to negatively regulate Wnt signalling and regulate cisplatinum resistance through regulating autophagy. EOC cells transfected with a lentivirus carrying fulllength DACT1 had increased levels of autophagy and were more sensitive to cisplatin ${ }^{[67]}$. In gastric cancer, 
NANOGP8 overexpression leads to anti-oxaliplatin (L-OHP) resistance. It upregulates EMT markers and increases $\beta$-catenin accumulation in the nucleus and strengthens Wnt signalling ${ }^{[68]}$. Activation of the Hh pathway has also been linked to drug resistance in both non-small cell lung cancer with resistance to EGFR-TKIs ${ }^{[61]}$ and in CRC with resistance to cetuximab ${ }^{[69]}$. Finally, the Notch pathway has been implicated in drug resistance in pancreatic cancer. Both Notch-2 and its ligand Jagged-1 are upregulated in gemcitabine-resistant cells and knockdown of Notch resulted in partial reversal of EMT characteristics ${ }^{[62]}$.

Numerous studies in a variety of tissue types have also found EMT-TFs, namely SNAIL1/2, ZEB1/2 and TWIST, to directly confer drug-resistance in cancer ${ }^{[70-81]}$, as summarised in Table 2. Upregulation of these transcription factors alone can be sufficient to confer drug resistance ${ }^{[71,75]}$. ZEB1 is highly expressed in glioblastoma cells, where a ZEB1-miR200 feedback loop connects this with a number of downstream targets (ROBO1, c-MYB and MGMT), and increased levels of this EMT-TF are associated with both drug resistance and reduced survival ${ }^{[79]}$. In CRC, the FBXW7-ZEB2 axis has been demonstrated to control a number of important EMT associated characteristics as well as drug resistance. ZEB2 knockdown was able to reverse the EMT phenotype induced by loss of FBXW7, a tumour suppressor ${ }^{[81]}$. Similarly, overexpression ${ }^{[70]}$ or upregulation ${ }^{[71,73]}$ of TWIST has resulted in chemoresistance in cancer cells; mechanistically, in bladder cancer, this has been shown to be through the upregulation of P-Glycoprotein $^{[72]}$. Several EMT-TFs including TWIST, SNAIL and FOXC2 have been shown to increase levels of $\mathrm{ABC}$ transporters. These are overexpressed in cancer and can remove cytotoxic drugs, and therefore increased levels confer drug resistance ${ }^{[77,78]}$. In cisplatin-resistant cell lines, both morphological and phenotypic hallmarks of EMT were identified; gene expression profiling identified several EMTTFs, including Snail1/2, which were further validated as key players in drug resistance ${ }^{[74]}$. These EMT mechanisms have been demonstrated in a wide-variety of cell lines/tissues including colon, breast, ovarian, gastric and glioblastoma cells, and with a number of different drugs, suggesting a significant issue.

\section{AUTOPHAGY AND DRUG RESISTANCE}

Autophagy has been implicated in drug resistance in malignancy; chemotherapeutic agents have been shown to be limited in their capacity. They were shown to induce protective-autophagy, and, subsequently, cancer cells became chemoresistant. Cisplatin, a commonly used platinum compound for the treatment of a number of cancers, including ovarian cancer, induces autophagy via ERK and this confers drug resistance in these cancer cells ${ }^{[82]}$. Further, inhibiting autophagy sensitised cancer cells to cisplatin-treatment ${ }^{[83,84]}$, with similar results also found in lung cancer ${ }^{[85]}$. In oesophageal cancer, cisplatin induced autophagy through the class III PI3K pathway and, when cisplatin was used together with autophagy inhibitor 3-Methyladenine, it augmented the effect of the treatment compared to cisplatin alone ${ }^{[86]}$.

Another example of this is 5-FU, which acts by inhibiting DNA synthesis ${ }^{[87]}$, although its ability is ultimately limited as it induces autophagy in cancer cells, which leads to chemoresistance. Several autophagy-related genes have been linked to multi-drug resistance in colorectal carcinoma ${ }^{[88]}$. Blocking autophagy was able to sensitise cancer cells to 5 -FU-mediated death ${ }^{[89,90]}$. c-Jun $\mathrm{N}$-terminal kinases (JNK) activation and phosphorylation of $\mathrm{Bcl}-2$ have been demonstrated as key components in 5-FU-induced autophagy in colon cancer $^{[89]}$, where $5-\mathrm{FU}$-induced autophagy protects cancer $\operatorname{cells}^{[87]}$. Similar findings have been shown in gallbladder carcinoma, where 5-FU also induced autophagy, and inhibition of autophagy with chloroquine was able to kill cancer cells ${ }^{[91]}$. Similar findings have been demonstrated in a range of other cancers, including estrogen receptor-positive breast cancer where autophagy inhibition can re-sensitise breast cancer cells to tamoxifen ${ }^{[92]}$. In prostate cancer, high levels of nitrogen permease regulator-like 2, a tumour suppressor candidate gene, can cause resistance to Everolimus by enhancing autophagy via mTOR ${ }^{[93]}$.

Apoptosis and autophagy are closely linked processes and often involved in crosstalk, and it is thought that drug-induced autophagy can protect cancer cells from apoptosis. In breast cancer cells, treatment with Epirubicin induced autophagy in MCF-7 cells and this protected them from drug-induced apoptosis. In drug-resistant MCF-7 cells, autophagy inhibition was able to re-sensitise cells to treatment ${ }^{[94]}$. Finally, three 
common chemotherapeutics used in the treatment of osteosarcoma induced upregulation of HSP90AA1, which was shown to be a regulator of autophagy via PI3K/Akt/mTOR and apoptosis via JNK/p38 ${ }^{[95]}$. Understanding the crosstalk of these pathways in the context of drug resistance will be critical in the development of new therapies.

Given that autophagy and EMT appear to have a complex relationship in malignancy, and that EMT has been demonstrated to contribute to drug resistance, a greater understanding of these relationships is key. New therapeutic strategies are being developed to try to target drug-resistance and targeting autophagy using inhibitors is one of the methods proposed, which was able to sensitise cells to chemotherapy ${ }^{[96-103]}$. Anti-cancer drugs have increasingly been utilised in combination with autophagy inhibitors. When cisplatin was used in combination with autophagy inhibition, this increased cytotoxicity in cells ${ }^{[48,104]}$ Similarly, the effects of 5-FU are augmented in colon cancer when treated with autophagy inhibitor hydroxychloroquine ${ }^{[105]}$.

\section{CONCLUSIONS AND FUTURE DIRECTIONS}

It is clear the underlying mechanisms in cancer drug resistance are multifaceted with several complex, interacting signalling pathways and processes contributing to resistance. These mechanisms are often highly specific, depending on tissue type and stage of disease. Although understanding the implications of these drugs alone on drug resistance is being better elucidated, understanding how these processes interact and the effect this may have on treatment is limited. In many cancers, autophagy inhibitors are being utilised with traditional therapies that can increase cytotoxicity of the drugs. Furthermore, anti-cancer drugs can become resistant through an upregulation of autophagy. However, autophagy inhibition in malignancy has been associated with EMT. Clinically, EMT, in addition to EMT-inducers and EMT-TF, has been linked to cancer-drug resistance. To best optimise treatment, it seems therapies need to be combined, targeted and tissue-specific.

\section{DECLARATIONS}

Authors' contributions

Conceptualisation and writing: Hill C and Wang Y

Supervision and funding acquisition: Wang $\mathrm{Y}$

\section{Availability of data and materials}

Not applicable.

\section{Financial support and sponsorship}

This project was supported by an Academy of Medical Sciences/the Wellcome Trust Springboard Award [SBF002 \1038] and Medical Research Council [MR/S025480/1]. CH was supported by Gerald Kerkut Charitable Trust and University of Southampton Central VC Scholarship Scheme.

\section{Conflicts of interest}

Both authors declared that there are no conflicts of interest.

\section{Ethical approval and consent to participate}

Not applicable.

\section{Consent for publication}

Not applicable.

\section{Copyright}

(C) The Author(s) 2020. 


\section{REFERENCES}

1. Kalluri R, Neilson EG. Epithelial-mesenchymal transition and its implications for fibrosis. J Clin Invest 2003;112:1776-84.

2. Thiery JP. Epithelial-mesenchymal transitions in development and pathologies. Curr Opin Cell Biol 2003;15:740-6.

3. Thiery JP, Acloque H, Huang RYJ, Nieto MA. Epithelial-mesenchymal transitions in development and disease. Cell 2009;139:871-90.

4. Barriere G, Fici P, Gallerani G, Fabbri F, Rigaud M. Epithelial mesenchymal transition: a double-edged sword. Clin Transl Med 2015;4:14.

5. Nieto MA, Huang RY, Jackson RA, Thiery JP. EMT: 2016. Cell 2016;166:21-45.

6. Lamouille S, Xu J, Derynck R. Molecular mechanisms of epithelial-mesenchymal transition. Nat Rev Mol Cell Biol 2014;15:178-96.

7. Peinado H, Olmeda D, Cano A. Snail, Zeb and bHLH factors in tumour progression: an alliance against the epithelial phenotype? Nat Rev Cancer 2007;7:415-28.

8. Onder TT, Gupta PB, Mani SA, Yang J, Lander ES, et al. Loss of E-cadherin promotes metastasis via multiple downstream transcriptional pathways. Cancer Res 2008;68:3645-54.

9. Vesuna F, van Diest P, ChenJH, Raman V. Twist is a transcriptional repressor of E-cadherin gene expression in breast cancer. Biochem Biophys Res Commun 2008;367:235-41.

10. Mizushima N, Ohsumi Y, Yoshimori T. Autophagosome formation in mammalian cells. Cell Struct Funct 2002;27:421-9.

11. Klionsky DJ, Emr SD. Autophagy as a regulated pathway of cellular degradation. Science 2000;290:1717-21.

12. Mizushima N, Komatsu M. Autophagy: renovation of cells and tissues. Cell 2011;147:728-41.

13. Bento CF, Renna M, Ghislat G, Puri C, Ashkenazi A, et al. Mammalian autophagy: how does it work? Ann Rev Biochem 2016;85:685-713.

14. Eskelinen EL, Saftig P. Autophagy: a lysosomal degradation pathway with a central role in health and disease. Biochim Biophys Acta 2009;1793:664-73.

15. Yorimitsu T, Klionsky DJ. Autophagy: molecular machinery for self-eating. Cell Death Differ 2005;12:1542-52.

16. Saha S, Panigrahi DP, Patil S, Bhutia SK. Autophagy in health and disease: a comprehensive review. Biomed Pharmacother 2018;104:485-95.

17. Araya J, Kojima J, Takasaka N, Ito S, Fujii S, et al. Insufficient autophagy in idiopathic pulmonary fibrosis. Am J Physiol Lung Cell Mol Physiol 2013;304:L56-69.

18. Patel AS, Lin L, Geyer A, Haspel JA, An CH, et al. Autophagy in idiopathic pulmonary fibrosis. PLoS One 2012;7:e41394.

19. Hill C, Li J, Liu D, Conforti F, Brereton CJ, et al. Autophagy inhibition-mediated epithelial-mesenchymal transition augments local myofibroblast differentiation in pulmonary fibrosis. Cell Death Dis 2019;10:591.

20. Harris H, Rubinsztein DC. Control of autophagy as a therapy for neurodegenerative disease. Nat Rev Neurol 2012;8:108-17.

21. Wang Y, Xiong H, Liu D, Hill C, Ertay A, et al. Autophagy inhibition specifically promotes epithelial-mesenchymal transition and invasion in RAS-mutated cancer cells. Autophagy 2019;15:886-99.

22. Levy JMM, Towers CG, Thorburn A. Targeting autophagy in cancer. Nat Rev Cancer 2017;17:528-42.

23. Singh SS, Vats S, Chia AYQ, Tan TZ, Deng S, et al. Dual role of autophagy in hallmarks of cancer. Oncogene 2018;37:1142-58.

24. Bhutia SK, Mukhopadhyay S, Sinha N, Das DN, Panda PK, et al. Autophagy: cancer's friend or foe? Adv Cancer Res 2013;118:61-95.

25. Rao S, Tortola L, Perlot T, Wirnsberger G, Novatchkova M, et al. A dual role for autophagy in a murine model of lung cancer. Nat Commun 2014;5:3056.

26. Takamura A, Komatsu M, Hara T, Sakamoto A, Kishi C, et al. Autophagy-deficient mice develop multiple liver tumors. Genes Dev 2011;25:795-800.

27. Lazova R, Camp RL, Klump V, Siddiqui SF, Amaravadi RK, et al. Punctate LC3B expression is a common feature of solid tumors and associated with proliferation, metastasis, and poor outcome. Clin Cancer Res 2012;18:370-9.

28. White E. Deconvoluting the context-dependent role for autophagy in cancer. Nat Rev Cancer 2012;12:401-10.

29. Sun K, Deng W, Zhang S, Cai N, Jiao S, et al. Paradoxical roles of autophagy in different stages of tumorigenesis: protector for normal or cancer cells. Cell Biosci 2013;3:35.

30. Classen F, Kranz P, Riffkin H, Pompsch M, Wolf A, et al. Autophagy induced by ionizing radiation promotes cell death over survival in human colorectal cancer cells. Exp Cell Res 2019;374:29-37.

31. Guo JY, Chen HY, Mathew R, Fan J, Strohecker AM, et al. Activated Ras requires autophagy to maintain oxidative metabolism and tumorigenesis. Genes Dev 2011;25:460-70.

32. Yang S, Wang X, Contino G, Liesa M, Sahin E, et al. Pancreatic cancers require autophagy for tumor growth. Genes Dev 2011;25:717-29.

33. Fitzwalter BE, Towers CG, Sullivan KD, Andrysik Z, Hoh M, et al. Autophagy inhibition mediates apoptosis sensitization in cancer therapy by relieving FOXO3a turnover. Dev Cell 2018;44:555-65.e3.

34. Rupniewska E, Roy R, Mauri FA, Liu X, Kaliszczak M, et al. Targeting autophagy sensitises lung cancer cells to Src family kinase inhibitors. Oncotarget 2018;9:27346-62.

35. Chen X, Clark J, Guan J, Kumar AR, Zheng Y. Susceptibility of AML to chloroquine therapy is independent of autophagy. Blood 2015;126:1262.

36. Gugnoni M, Sancisi V, Manzotti G, Gandolfi G, Ciarrocchi A. Autophagy and epithelial-mesenchymal transition: an intricate interplay in cancer. Cell Death Dis 2016;7:e2520.

37. Chen HT, Liu H, Mao MJ, Tan Y, Mo XQ, et al. Crosstalk between autophagy and epithelial-mesenchymal transition and its application in cancer therapy. Mol Cancer 2019;18:101.

38. Qin W, Li C, Zheng W, Guo Q, Zhang Y, et al. Inhibition of autophagy promotes metastasis and glycolysis by inducing ROS in gastric cancer cells. Oncotarget 2015;6:39839-54.

39. Alizadeh J, Glogowska A, Thliveris J, Kalantari F, Shojaei S, et al. Autophagy modulates transforming growth factor beta 1 induced epithelial to mesenchymal transition in non-small cell lung cancer cells. Biochim Biophys Acta Mol Cell Res 2018;1865:749-68.

40. Qiang L, He YY. Autophagy deficiency stabilizes TWIST1 to promote epithelial-mesenchymal transition. Autophagy 2014;10:1864-5.

41. Shen H, Yin L, Deng G, Guo C, Han Y, et al. Knockdown of Beclin-1 impairs epithelial-mesenchymal transition of colon cancer cells. 
J Cell Biochem 2018;119:7022-31.

42. Liang C, Xu J, Meng Q, Zhang B, Liu J, et al. TGFB1-induced autophagy affects the pattern of pancreatic cancer progression in distinct ways depending on SMAD4 status. Autophagy 2019:1-15.

43. Peng YF, Shi YH, Ding ZB, Ke AW, Gu CY, et al. Autophagy inhibition suppresses pulmonary metastasis of HCC in mice via impairing anoikis resistance and colonization of HCC cells. Autophagy 2013;9:2056-68.

44. Lv Q, Hua F, Hu ZW. DEDD, a novel tumor repressor, reverses epithelial-mesenchymal transition by activating selective autophagy. Autophagy 2012;8:1675-6.

45. Zi D, Zhou ZW, Yang YJ, Huang L, Zhou ZL, et al. Danusertib induces apoptosis, cell cycle arrest, and autophagy but inhibits epithelial to mesenchymal transition involving PI3K/Akt/mTOR signaling pathway in human ovarian cancer cells. Int J Mol Sci 2015; 16:27228-51.

46. Wei R, Xiao Y, Song Y, Yuan H, Luo J, et al. FAT4 regulates the EMT and autophagy in colorectal cancer cells in part via the PI3KAKT signaling axis. J Exp Clin Cancer Res 2019;38:112.

47. Avivar-Valderas A, Bobrovnikova-Marjon E, Alan Diehl J, Bardeesy N, Debnath J, et al. Regulation of autophagy during ECM detachment is linked to a selective inhibition of mTORC1 by PERK. Oncogene 2013;32:4932-40.

48. Su Z, Li G, Liu C, Ren S, Deng T, et al. Autophagy inhibition impairs the epithelial-mesenchymal transition and enhances cisplatin sensitivity in nasopharyngeal carcinoma. Oncol Lett 2017;13:4147-54.

49. Wei R, Xiao Y, Song Y, Yuan H, Luo J, et al. FAT4 regulates the EMT and autophagy in colorectal cancer cells in part via the PI3KAKT signaling axis. J Exp Clin Cancer Res 2019;38:112.

50. Nikolaou M, Pavlopoulou A, Georgakilas AG, Kyrodimos E. The challenge of drug resistance in cancer treatment: a current overview. Clin Exp Metastasis 2018;35:309-18.

51. Housman G, Byler S, Heerboth S, Lapinska K, Longacre M, et al. Drug resistance in cancer: an overview. Cancers (Basel) 2014;6:1769-92.

52. Sommers CL, Heckford SE, Skerker JM, Worland P, Torri JA, et al. Loss of epithelial markers and acquisition of vimentin expression in adriamycin- and vinblastine-resistant human breast cancer cell lines. Cancer Res 1992;52:5190-7.

53. Fischer KR, Durrans A, Lee S, Sheng J, Li F, et al. Epithelial-to-mesenchymal transition is not required for lung metastasis but contributes to chemoresistance. Nature 2015;527:472-6.

54. Arumugam T, Ramachandran V, Fournier KF, Wang H, Marquis L, et al. Epithelial to mesenchymal transition contributes to drug resistance in pancreatic cancer. Cancer Res 2009;69:5820-8.

55. Zheng X, Carstens JL, Kim J, Scheible M, Kaye J, et al. Epithelial-to-mesenchymal transition is dispensable for metastasis but induces chemoresistance in pancreatic cancer. Nature 2015;527:525-30.

56. McConkey DJ, Choi W, Marquis L, Martin F, Williams MB, et al. Role of epithelial-to-mesenchymal transition (EMT) in drug sensitivity and metastasis in bladder cancer. Cancer Metastasis Rev 2009;28:335-44.

57. Huang J, Li H, Ren G. Epithelial-mesenchymal transition and drug resistance in breast cancer (Review). Int J Oncol 2015;47:840-8.

58. Saxena M, Stephens MA, Pathak H, Rangarajan A. Transcription factors that mediate epithelial-mesenchymal transition lead to multidrug resistance by upregulating ABC transporters. Cell Death Dis 2011;2:e179.

59. Li J, Liu H, Yu J, Yu H. Chemoresistance to doxorubicin induces epithelial-mesenchymal transition via upregulation of transforming growth factor $\beta$ signaling in HCT116 colon cancer cells. Mol Med Rep 2015;12:192-8.

60. Wu Y, Ginther C, Kim J, Mosher N, Chung S, et al. Expression of Wnt3 activates Wnt/-catenin pathway and promotes EMT-like phenotype in trastuzumab-resistant HER2-overexpressing breast cancer cells. Mol Cancer Res 2012;10:1597-606.

61. Della Corte CM, Bellevicine C, Vicidomini G, Vitagliano D, Malapelle U, et al. SMO gene amplification and activation of the hedgehog pathway as novel mechanisms of resistance to anti-epidermal growth factor receptor drugs in human lung cancer. Clin Cancer Res 2015;21:4686-97.

62. Wang Z, Li Y, Kong D, Banerjee S, Ahmad A, et al. Acquisition of epithelial-mesenchymal transition phenotype of gemcitabineresistant pancreatic cancer cells is linked with activation of the notch signaling pathway. Cancer Res 2009;69:2400-7.

63. Xu X, Zhang L, He X, Zhang P, Sun C, et al. TGF- $\beta$ plays a vital role in triple-negative breast cancer (TNBC) drug-resistance through regulating stemness, EMT and apoptosis. Biochem Biophys Res Commun 2018;502:160-5.

64. Oshimori N, Oristian D, Fuchs E. TGF- $\beta$ promotes heterogeneity and drug resistance in squamous cell carcinoma. Cell 2015;160:963-76.

65. Katsuno Y, Meyer DS, Zhang Z, Shokat KM, Akhurst RJ, et al. Chronic TGF- $\beta$ exposure drives stabilized EMT, tumor stemness, and cancer drug resistance with vulnerability to bitopic mTOR inhibition. Sci Signal 2019;12:eaau8544.

66. Zhang Y, Zhang Y, Geng L, Yi H, Huo W, et al. Transforming growth factor $\beta$ mediates drug resistance by regulating the expression of pyruvate dehydrogenase kinase 4 in colorectal cancer. J Biol Chem 2016;291:17405-16.

67. Li RN, Liu B, Li XM, Hou LS, Mu XL, et al. DACT1 overexpression in type I ovarian cancer inhibits malignant expansion and cisplatinum resistance by modulating canonical Wnt signalling and autophagy. Sci Rep 2017;7:9285.

68. Ma X, Wang B, Wang X, Luo Y, Fan W. NANOGP8 is the key regulator of stemness, EMT, Wnt pathway, chemoresistance, and other malignant phenotypes in gastric cancer cells. PloS One 2018;13:e0192436.

69. Park SH, Jo MJ, Kim BR, Jeong YA, Na YJ, et al. Sonic hedgehog pathway activation is associated with cetuximab resistance and EPHB3 receptor induction in colorectal cancer. Theranostics 2019;9:2235-51.

70. Deng JJ, Zhang W, Xu XM, Zhang F, Tao WP, et al. Twist mediates an aggressive phenotype in human colorectal cancer cells. Int J Oncol 2016;48:1117-24.

71. Wang X, Ling MT, Guan XY, Tsao SW, Cheung HW, et al. Identification of a novel function of TWIST, a bHLH protein, in the development of acquired taxol resistance in human cancer cells. Oncogene 2004;23:474-82.

72. Chen Y, Li L, Zeng J, Wu K, Zhou J, et al. Twist confers chemoresistance to anthracyclines in bladder cancer through upregulating P-glycoprotein. Chemotherapy 2012;58:264-72.

73. Wang L, Tan RZ, Zhang ZX, Yin R, Zhang YL, et al. Association between Twist and multidrug resistance gene-associated proteins in Taxol(囚)-resistant MCF-7 cells and a 293 cell model of Twist overexpression. Oncol Lett 2018;15:1058-66. 
74. Haslehurst AM, Koti M, Dharsee M, Nuin P, Evans K, et al. EMT transcription factors snail and slug directly contribute to cisplatin resistance in ovarian cancer. BMC Cancer 2012;12:91.

75. Hojo N, Huisken AL, Wang H, Chirshev E, Kim NS, et al. Snail knockdown reverses stemness and inhibits tumour growth in ovarian cancer. Sci Rep 2018;8:8704.

76. Nakamura R, Ishii H, Endo K, Hotta A, Fujii E, et al. Reciprocal expression of Slug and Snail in human oral cancer cells. PLoS One 2018;13:e0199442.

77. Choi $\mathrm{CH} . \mathrm{ABC}$ transporters as multidrug resistance mechanisms and the development of chemosensitizers for their reversal. Cancer Cell Int 2005;5:30.

78. Saxena M, Stephens MA, Pathak H, Rangarajan A. Transcription factors that mediate epithelial-mesenchymal transition lead to multidrug resistance by upregulating ABC transporters. Cell Death Dis 2011;2:e179.

79. Siebzehnrubl FA, Silver DJ, Tugertimur B, Deleyrolle LP, Siebzehnrubl D, et al. The ZEB1 pathway links glioblastoma initiation, invasion and chemoresistance. EMBO Mol Med 2013;5:1196-212.

80. Li Y, Wang L, Pappan L, Galliher-Beckley A, Shi J. IL-1 $\beta$ promotes stemness and invasiveness of colon cancer cells through Zeb1 activation. Mol Cancer 2012;11:87.

81. Li N, Babaei-Jadidi R, Lorenzi F, Spencer-Dene B, Clarke P, et al. An FBXW7-ZEB2 axis links EMT and tumour microenvironment to promote colorectal cancer stem cells and chemoresistance. Oncogenesis 2019;8:13.

82. Wang J, Wu GS. Role of autophagy in cisplatin resistance in ovarian cancer cells. J Biol Chem 2014;289:17163-73.

83. Bao L, Jaramillo MC, Zhang Z, Zheng Y, Yao M, et al. Induction of autophagy contributes to cisplatin resistance in human ovarian cancer cells. Mol Med Rep 2015;11:91-8.

84. You Y, Bi FF, Jiang Y, Xu YT, An YY, et al. BRCA1 affects the resistance and stemness of SKOV3-derived ovarian cancer stem cells by regulating autophagy. Cancer Med 2019;8:656-68.

85. Lee JG, Shin JH, Shim HS, Lee CY, Kim DJ, et al. Autophagy contributes to the chemo-resistance of non-small cell lung cancer in hypoxic conditions. Respir Res 2015;16:138.

86. Liu D, Yang Y, Liu Q, Wang J. Inhibition of autophagy by 3-MA potentiates cisplatin-induced apoptosis in esophageal squamous cell carcinoma cells. Med Oncol 2011;28:105-11.

87. Park JM, Huang S, Wu TT, Foster NR, Sinicrope FA. Prognostic impact of Beclin 1, p62/sequestosome 1 and LC3 protein expression in colon carcinomas from patients receiving 5-fluorouracil as adjuvant chemotherapy. Cancer Biol Ther 2013;14:100-7.

88. Shuhua W, Chenbo S, Yangyang L, Xiangqian G, Shuang H, et al. Autophagy-related genes Raptor, Rictor, and Beclin1 expression and relationship with multidrug resistance in colorectal carcinoma. Hum Pathol 2015;46:1752-9.

89. Sui X, Kong N, Wang X, Fang Y, Hu X, et al. JNK confers 5-fluorouracil resistance in p53-deficient and mutant p53-expressing colon cancer cells by inducing survival autophagy. Sci Rep 2014;4:4694.

90. Li J, Hou N, Faried A, Tsutsumi S, Kuwano H. Inhibition of autophagy augments 5-fluorouracil chemotherapy in human colon cancer in vitro and in vivo model. Eur J Cancer 2010;46:1900-9.

91. Liang X, Tang J, Liang Y, Jin R, Cai X. Suppression of autophagy by chloroquine sensitizes 5-fluorouracil-mediated cell death in gallbladder carcinoma cells. Cell Biosci 2014;4:10.

92. Samaddar JS, Gaddy VT, Duplantier J, Thandavan SP, Shah M, et al. A role for macroautophagy in protection against 4-hydroxytamoxifen-induced cell death and the development of antiestrogen resistance. Mol Cancer Ther 2008;7:2977.

93. Chen Z, Jiang Q, Zhu P, Chen Y, Xie X, et al. NPRL2 enhances autophagy and the resistance to Everolimus in castration-resistant prostate cancer. Prostate 2019;79:44-53.

94. Sun WL, Chen J, Wang YP, Zheng H. Autophagy protects breast cancer cells from epirubicin-induced apoptosis and facilitates epirubicin-resistance development. Autophagy 2011;7:1035-44.

95. Xiao X, Wang W, Li Y, Yang D, Li X, et al. HSP90AA1-mediated autophagy promotes drug resistance in osteosarcoma. J Exp Clin Cancer Res 2018;37:201.

96. An Y, Zhang Z, Shang Y, Jiang X, Dong J, et al. miR-23b-3p regulates the chemoresistance of gastric cancer cells by targeting ATG12 and HMGB2. Cell Death Dis 2015;6:e1766.

97. O'Donovan TR, O'Sullivan GC, McKenna SL. Induction of autophagy by drug-resistant esophageal cancer cells promotes their survival and recovery following treatment with chemotherapeutics. Autophagy 2011;7:509-24.

98. Zhang LH, Yang AJ, Wang M, Liu W, Wang CY, et al. Enhanced autophagy reveals vulnerability of P-gp mediated epirubicin resistance in triple negative breast cancer cells. Apoptosis 2016;21:473-88.

99. Zhang N, Qi Y, Wadham C, Wang L, Warren A, et al. FTY720 induces necrotic cell death and autophagy in ovarian cancer cells: a protective role of autophagy. Autophagy 2010;6:1157-67.

100. Fan QW, Cheng C, Hackett C, Feldman M, Houseman BT, et al. Akt and autophagy cooperate to promote survival of drug-resistant glioma. Sci Signal 2010;3:ra81.

101. Ahn JH, Lee M. Suppression of autophagy sensitizes multidrug resistant cells towards Src tyrosine kinase specific inhibitor PP2. Cancer Lett 2011;310:188-97.

102. Carew JS, Nawrocki ST, Kahue CN, Zhang H, Yang C, et al. Targeting autophagy augments the anticancer activity of the histone deacetylase inhibitor SAHA to overcome Bcr-Abl-mediated drug resistance. Blood 2007;110:313.

103. Ge J, Chen Z, Huang J, Chen J, Yuan W, et al. Upregulation of autophagy-related gene-5 (ATG-5) is associated with chemoresistance in human gastric cancer. PLoS One 2014;9:e110293.

104. Claerhout S, Verschooten L, Van Kelst S, De Vos R, Proby C, et al. Concomitant inhibition of AKT and autophagy is required for efficient cisplatin-induced apoptosis of metastatic skin carcinoma. Int J Cancer 2010;127:2790-803.

105. Sasaki K, Tsuno NH, Sunami E, Tsurita G, Kawai K, et al. Chloroquine potentiates the anti-cancer effect of 5-fluorouracil on colon cancer cells. BMC Cancer 2010;10:370. 